Check for updates

Cite this: RSC Adv., 2019, 9, 13112

\title{
Immobilized antimony species on magnetite: a novel and highly efficient magnetically reusable nanocatalyst for direct and gram-scale reductive- coupling of nitroarenes to azoarenes $\dagger$
}

\begin{abstract}
Behzad Zeynizadeh (D) * and Fariba Faraji
In this study, magnetic nanoparticles of $\mathrm{Fe}_{3} \mathrm{O}_{4} \mathrm{aSbF}_{x}$ from the immobilization of $\mathrm{SbF}_{3}$ on magnetite were synthesized. The prepared nanocomposite system was then characterized using scanning electron microscopy, Fourier transform infrared spectroscopy, X-ray diffraction, energy-dispersive X-ray spectroscopy, vibrating sample magnetometry and inductively coupled plasma optical emission spectroscopy. Next, the catalytic activity of $\mathrm{Fe}_{3} \mathrm{O}_{4} \mathrm{aSbF}_{x}$ MNPs was highlighted by one-pot reductivecoupling of aromatic nitro compounds to the corresponding azoarene materials with $\mathrm{NaBH}_{4}$. The reactions were carried out in refluxing $\mathrm{EtOH}$ within 6-25 $\mathrm{min}$ to afford the products in high yields. The reusability of the Sb-magnetite system was also studied for 6 consecutive cycles without significant loss of catalytic activity. This synthetic protocol provided several advantages in terms of introducing a novel catalytic system based on antimony species for direct and gram-scale preparation of azoarenes from nitroarenes, low loading of the nanocatalyst, mild reaction conditions, using ethanol as a green and economic solvent and high yield of the products.
\end{abstract}

Received 18th February 2019

Accepted 23rd April 2019

DOI: $10.1039 / c 9 r a 01249 d$

rsc.li/rsc-advances course, the multistep preparation of azoarenes has been extensively reviewed by Merino. ${ }^{19}$ Although most of the reported protocols provided the useful synthetic capabilities, however, they generally suffer from low to moderate yield of the products, the prolonged reaction times, cyclization, isomerization and rearrangement reactions..$^{20,21}$ To overcome the mentioned shortcomings, several synthetic methods through the improvement of the catalyst activity have been reported. ${ }^{22,23} \mathrm{In}$ contrast to the multistep strategy, the straightforward oxidativecoupling of aromatic amines to azoarenes ${ }^{24-26}$ and reductivecoupling of nitroarenes to azoxyarenes ${ }^{27-33}$ was also a subject of more interest. In this context, the application of $\mathrm{HCOONH}_{4} /$ $\mathrm{Pb},{ }^{34} \mathrm{CH}_{3} \mathrm{COONH}_{4} / \mathrm{Pb},{ }^{35} \mathrm{HCOONHEt}_{3} / \mathrm{Pb},{ }^{36} \mathrm{HCOONHEt}_{3} / \mathrm{Mg}^{37}$ $\mathrm{LiAlH}_{4},{ }^{38} \mathrm{NaH}_{2} \mathrm{Al}\left(\mathrm{OCH}_{2} \mathrm{CH}_{2} \mathrm{OMe}\right)_{2},{ }^{39} \mathrm{NaBH}_{4} / \mathrm{DMSO}^{40}(\mathrm{MeCN})_{3}{ }^{-}$ $\mathrm{Cr}(\mathrm{CO})_{3},{ }^{41} \mathrm{Co}_{2}(\mathrm{CO})_{8},{ }^{42} \mathrm{HOCH}_{2} \mathrm{CH}_{2} \mathrm{ONa},{ }^{43} \mathrm{Zn} / \mathrm{NaOH},{ }^{44} \mathrm{Bi} / \mathrm{KOH},{ }^{45}$ $\mathrm{Mg} / \mathrm{NH}_{4} \mathrm{Br},{ }^{46} \mathrm{Mg} / \mathrm{MeOH},{ }^{47} \mathrm{Mg} / \mathrm{MCl}_{n}\left(\mathrm{MCl}_{n}: \mathrm{TiCl}_{4}, \mathrm{VCl}_{3}, \mathrm{CrCl}_{3}\right.$, $\mathrm{MoOCl}_{3}, \mathrm{WCl}_{6}$ and $\left.\mathrm{FeCl}_{3}\right),{ }^{48} \mathrm{Pd}(\mathrm{acac})_{2} / \mathrm{H}_{2},{ }^{49} \mathrm{InBr}_{3} / \mathrm{Et}_{3} \mathrm{SiH},{ }^{50}$ $\mathrm{In}(\mathrm{OTf})_{3} / \mathrm{Et}_{3} \mathrm{SiH} / \mathrm{O}_{2},{ }^{51} \quad \mathrm{FeCl}_{2} \cdot 4 \mathrm{H}_{2} \mathrm{O} / \mathrm{Li} / \mathrm{DTBB},{ }^{52} \quad$ electroreduction, ${ }^{53} \mathrm{Au} / \mathrm{meso} \mathrm{CeO}_{2} / \mathrm{CO},{ }^{54} \mathrm{Li} / \mathrm{THF},{ }^{55} \mathrm{Bi} / \mathrm{ball}$ mill ${ }^{56}$ and $\mathrm{Cr}^{57}$ has also been documented for direct conversion of nitroarenes to azoarene materials.

It is also known that in the promoted reactions by metal nanoparticles, the electronic influence of metal species, nano-size dimension of particles and porosity of the surface play the synergic roles to improve the rate of examined reactions. However, metal nanoparticles generally due van der Waals, electrostatic or magnetic forces represent a strong tendency for agglomeration
Faculty of Chemistry, Urmia University, Urmia 5756151818, Iran. E-mail: bzeynizadeh@gmail.com; Fax: +98-44-32755294; Tel: +98-44-32755294

$\dagger$ Electronic supplementary information (ESI) available. See DOI: $10.1039 /$ c9ra01249d 
while it decreases the active surface area and catalytic activity of the applied catalyst system. In order to overcome this shortcoming and preserve the original characteristics of nanoparticles, the immobilization of metal nanoparticles on organic and inorganic stabilizers/supports has been frequently documented. Organic ligand, ${ }^{58}$ polymer, ${ }^{59}$ zeolites, $^{60,61}$ reduced graphene oxide, ${ }^{62-65}$ $\mathrm{CuO}^{66}{ }^{6 u m s}{ }^{67}$ and magnetic materials ${ }^{68}$ are the stabilizers which have been successfully served for the immobilization of metal nanoparticles. Among these, the magnetic nanoparticles (MNPs) of $\mathrm{Fe}_{3} \mathrm{O}_{4}$ due extreme specific surface area, high magnetic property, chemical solidity and ease of preparation and separation are more appropriate for anchoring the metal species. ${ }^{69}$

In line with the outlined strategies and continuation of our research program directed to synthetic usefulness of magnetic nanocatalysts, ${ }^{\mathbf{7 0 - 7 6}}$ herein, we wish to report synthesis of the immobilized antimony species on magnetite, $\mathrm{Fe}_{3} \mathrm{O}_{4} @ \mathrm{SbF}_{x}$, as novel, highly efficient and reusable magnetic nanocatalyst for straightforward reductive-coupling of nitroarenes to symmetrically substituted azoarene materials in refluxing EtOH (Scheme 1).

\section{Results and discussion}

\section{Preparation and characterization of $\mathrm{Fe}_{3} \mathrm{O}_{4} @ \mathrm{SbF}_{x} \mathrm{MNPs}$}

The study was started by preliminary preparation of magnetically nanoparticles of $\mathrm{Fe}_{3} \mathrm{O}_{4} @ \mathrm{SbF}_{x}$ with $15 \% \mathrm{Sb}$ species via a two-step procedure: (i) preparation of $\mathrm{Fe}_{3} \mathrm{O}_{4}$ MNPs by chemical co-precipitation of $\mathrm{FeCl}_{3} \cdot 6 \mathrm{H}_{2} \mathrm{O}$ and $\mathrm{FeCl}_{2} \cdot 4 \mathrm{H}_{2} \mathrm{O}$ in aqueous ammonia and (ii) the immobilization of $\mathrm{SbF}_{x}$ on magnetite by simply mixing of an aqueous solution of $\mathrm{SbF}_{3}$ with $\mathrm{Fe}_{3} \mathrm{O}_{4} \mathrm{MNPS}$ under reflux conditions (Scheme 2).

\section{Characterization of $\mathrm{Fe}_{3} \mathrm{O}_{4} @ \mathrm{SbF}_{x} \mathrm{MNPs}$}

After the successful synthesis of $\mathrm{Fe}_{3} \mathrm{O}_{4} @ \mathrm{SbF}_{x}$ MNPs, the nanocatalyst was then characterized using Fourier transform infrared spectroscopy (FT-IR), scanning electron microscopy (SEM), energy-dispersive X-ray spectroscopy (EDX), X-ray diffraction (XRD), vibrating sample magnetometer (VSM), $\mathrm{N}_{2}$ adsorption-desorption analysis and inductively coupled plasma-optical emission spectroscopy (ICP-OES).

\section{FT-IR analysis}

Fourier transform infrared spectroscopy as a primarily tool was used for structural elucidation of $\mathrm{Fe}_{3} \mathrm{O}_{4}$ and $\mathrm{Fe}_{3} \mathrm{O}_{4} @ \mathrm{SbF}_{x}$ MNPs. In this context, FT-IR spectrum of $\mathrm{Fe}_{3} \mathrm{O}_{4}$ (Fig. 1a) shows a strong absorption band at $575 \mathrm{~cm}^{-1}$ showing the stretching vibration of $\mathrm{Fe}-\mathrm{O}$ bond. The absorption peaks at 1625 and $3400 \mathrm{~cm}^{-1}$ are also attributed to $\mathrm{O}-\mathrm{H}$ deforming and stretching vibrations of adsorbed water, respectively. FT-IR spectrum of $\mathrm{Fe}_{3} \mathrm{O}_{4} @ \mathrm{SbF}_{x}$ MNPs (Fig. 1b) also
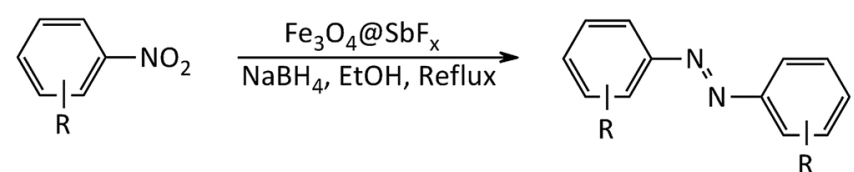

Scheme 1 Synthesis of azoarenes catalyzed by $\mathrm{NaBH}_{4} / \mathrm{Fe}_{3} \mathrm{O}_{4} \mathrm{aSbF}$ MNPs system.

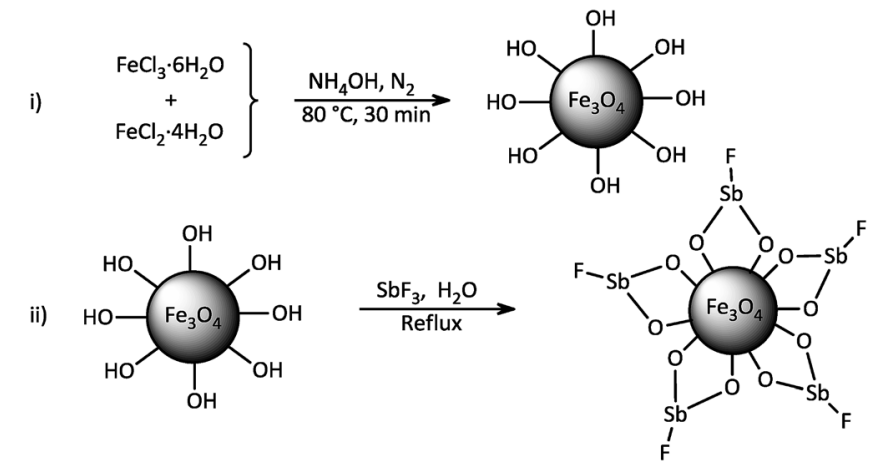

Scheme 2 Synthesis of magnetically nanoparticles of $\mathrm{Fe}_{3} \mathrm{O}_{4} \propto \mathrm{SbF}_{x}$.

shows the absorption peaks at 3421 and $1631 \mathrm{~cm}^{-1}$ related to the stretching and bending vibrations of $\mathrm{OH}$ groups on the surface of nanoparticles. The peaks around 1021 and $566 \mathrm{~cm}^{-1}$ are respectively attributed to stretching vibrations of $\mathrm{Sb}-\mathrm{O}$ and $\mathrm{Sb}-\mathrm{F}$ bonds. Therefore, the later absorption bands successfully verify the immobilization of $\mathrm{SbF}_{x}$ species on the surface of magnetite.

\section{SEM analysis}

Morphology of the surface and size distribution of nanoparticles in $\mathrm{Fe}_{3} \mathrm{O}_{4}$ and $\mathrm{Fe}_{3} \mathrm{O}_{4} @ \mathrm{SbF}_{x}$ MNPs were also investigated using scanning electron microscopy technique (Fig. 2). The surfacemicroscopy image of $\mathrm{Fe}_{3} \mathrm{O}_{4}$ MNPs (Fig. 2a) represents that the magnetite was constituted from uniform and ultrafine granular particles distributed in the range of 10-21 nm. As well, SEM image of $\mathrm{Fe}_{3} \mathrm{O}_{4} @ \mathrm{SbF}_{x}$ MNPs (Fig. 2b) shows that through the reaction of magnetite with $\mathrm{SbF}_{3}$, the surface of Sb-magnetite was thoroughly modified and constituted from porous and uniform granular nanoparticles distributed in the range of 45-68 nm.

\section{EDX analysis}

Energy-dispersive X-ray (EDX) spectroscopy as an effective technique was used to determine the presence of elements in a material. According to the depicted graphs for EDX analysis of $\mathrm{Fe}_{3} \mathrm{O}_{4}$ and $\mathrm{Fe}_{3} \mathrm{O}_{4} @ \mathrm{SbF}_{x}$ MNPs (Fig. 3), the presence of $\mathrm{Fe}$ and $\mathrm{O}$ in $\mathrm{Fe}_{3} \mathrm{O}_{4}$ as well $\mathrm{Fe}, \mathrm{O}$, $\mathrm{Sb}$ and $\mathrm{F}$ elements in $\mathrm{Fe}_{3} \mathrm{O}_{4} @ \mathrm{SbF}_{x} \mathrm{MNPs}$

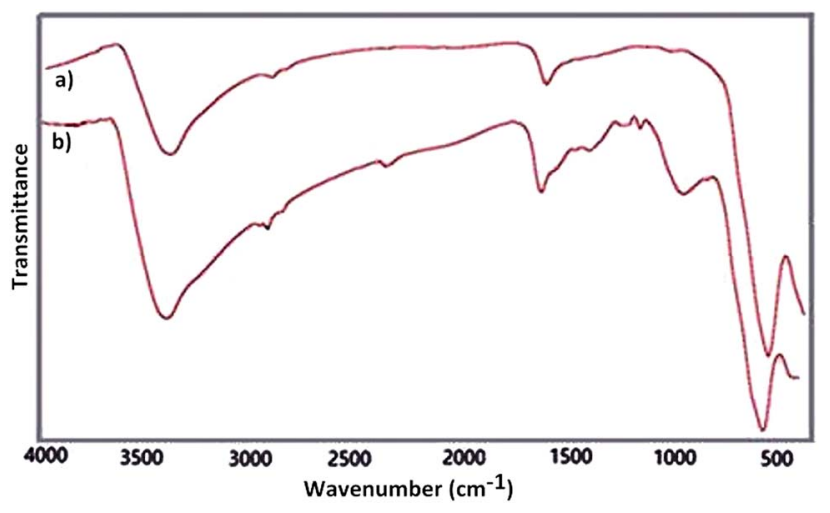

Fig. 1 FT-IR spectra of (a) $\mathrm{Fe}_{3} \mathrm{O}_{4}$ and (b) $\mathrm{Fe}_{3} \mathrm{O}_{4} \mathrm{aSbF}_{x}$ MNPs. 

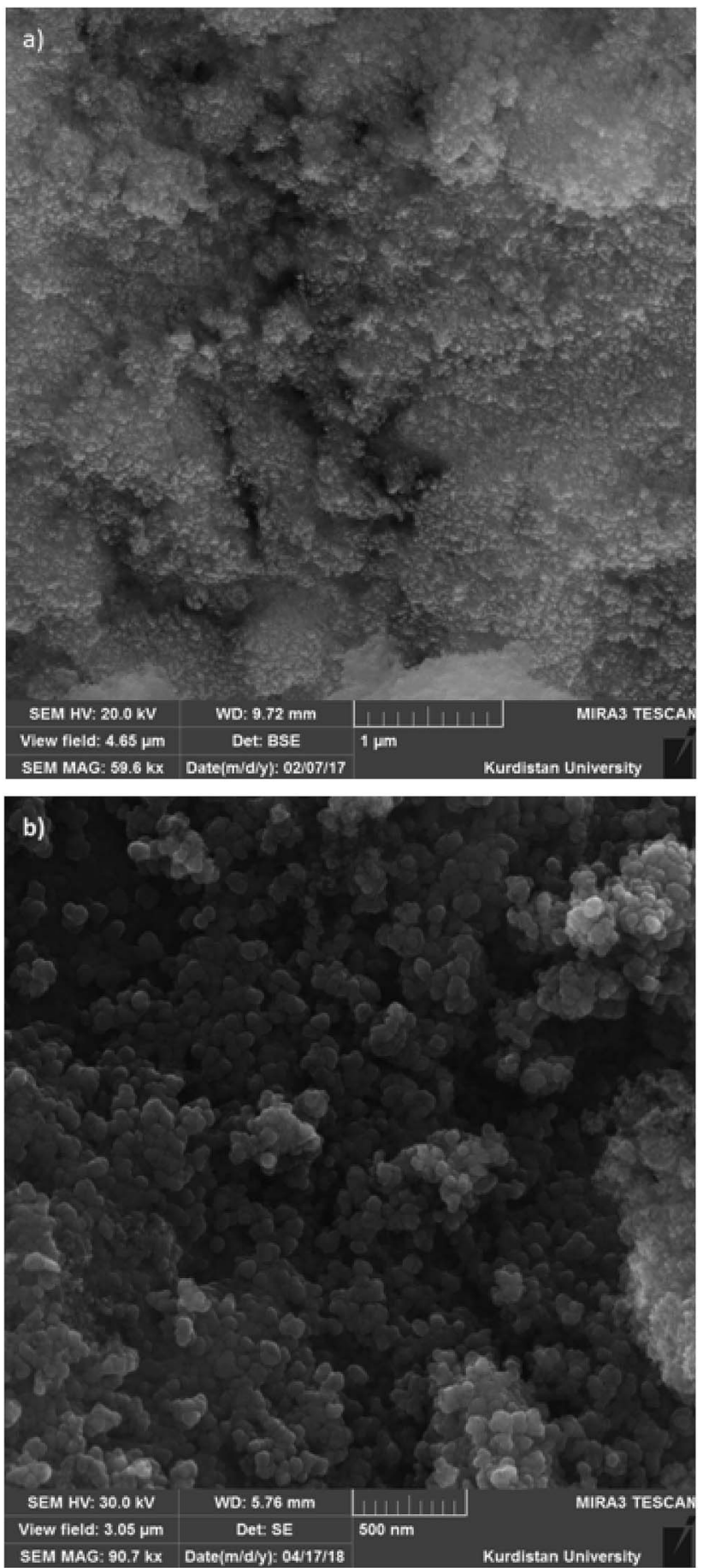

Fig. 2 SEM images of (a) $\mathrm{Fe}_{3} \mathrm{O}_{4}$ and (b) $\mathrm{Fe}_{3} \mathrm{O}_{4}\left(\mathrm{aSbF}_{x}\right.$ MNPs.

is proved. This analysis clearly shows the successful immobilization of $\mathrm{SbF}_{x}$ species on the surface of $\mathrm{Fe}_{3} \mathrm{O}_{4}$.

\section{ICP-OES analysis}

In continuation to EDX analysis, the exact amounts of $\mathrm{Fe}$ and $\mathrm{Sb}$ in $\mathrm{Fe}_{3} \mathrm{O}_{4} @ \mathrm{SbF}_{x}$ MNPs were determined by inductively coupled plasma optical emission spectroscopy (ICP-OES). Based on this analysis, the amounts of $\mathrm{Sb}$ and $\mathrm{Fe}$ in $\mathrm{Fe}_{3} \mathrm{O}_{4} @ \mathrm{SbF}_{x}$ MNPs were found to be $15.06 \%$ and $54.1 \%$, respectively.
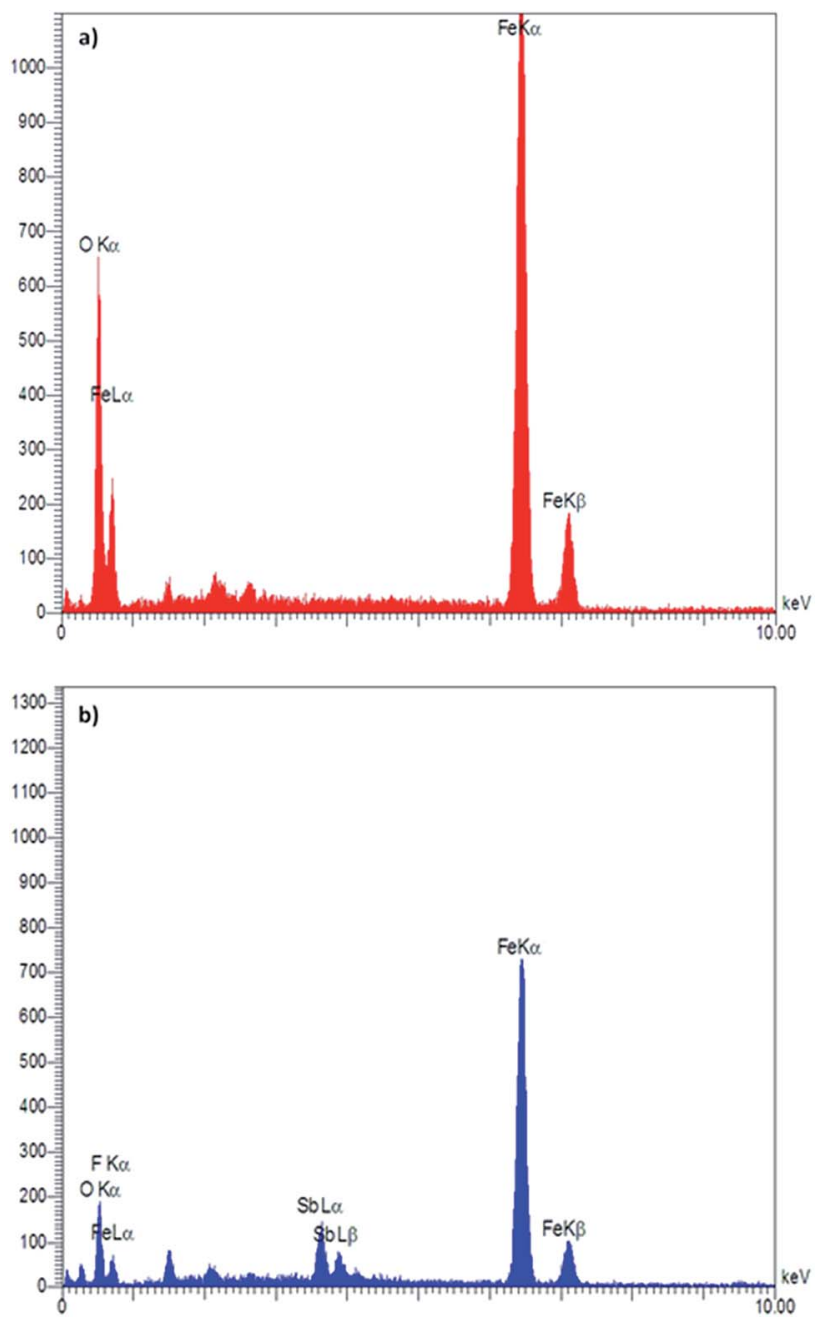

Fig. 3 EDX spectra of (a) $\mathrm{Fe}_{3} \mathrm{O}_{4}$ and (b) $\mathrm{Fe}_{3} \mathrm{O}_{4}\left(\mathrm{aSbF}_{x}\right.$ MNPs.

\section{XRD analysis}

At the next, the phase purity and crystallinity structure of the prepared nanocatalysts was determined using X-ray diffraction (XRD) analysis. Fig. 4 represents XRD diffractograms of $\mathrm{Fe}_{3} \mathrm{O}_{4}$ and $\mathrm{Fe}_{3} \mathrm{O}_{4} @ \mathrm{SbF}_{x}$ MNPs. In XRD pattern of $\mathrm{Fe}_{3} \mathrm{O}_{4}$, the peaks at $2 \theta=30.2^{\circ}, 35.5^{\circ}, 43.3^{\circ}, 53.7^{\circ}, 57.2^{\circ}$ and $62.9^{\circ}$ are attributed to (220), (311), (400), (422), (511) and (440) reflection planes of cubic spinal $\mathrm{Fe}_{3} \mathrm{O}_{4}$ (JCPDS 65-3107). ${ }^{77,78}$ In XRD pattern of $\mathrm{Fe}_{3}$ $\mathrm{O}_{4} @ \mathrm{SbF}_{x}$ MNPs (Fig. 4b), the presence of characteristic peaks related to $\mathrm{Fe}_{3} \mathrm{O}_{4}$ is verifying that during the immobilization of $\mathrm{Sb}$ species, no structural change has been taken place in the spinal structure of magnetite. Moreover, the absorption peak at $2 \theta=26^{\circ}$ is exactly attributed to the bond of $\mathrm{Sb}-\mathrm{F}$ showing the immobilization of $\mathrm{Sb}$ species on the surface of $\mathrm{Fe}_{3} \mathrm{O}_{4}$ MNPs. ${ }^{79}$

\section{BET analysis}

The porosity and surface characteristics of $\mathrm{Fe}_{3} \mathrm{O}_{4} @ \mathrm{SbF}_{x} \mathrm{MNPs}$ was studied through the $\mathrm{N}_{2}$ adsorption-desorption analysis. The results of this investigation are illustrated in Fig. 5. According to categories of adsorption isotherms (BDDT), the shape of isotherm for $\mathrm{Fe}_{3} \mathrm{O}_{4} @ \mathrm{SbF}_{x} \mathrm{MNPs}$ is belonged to type of 


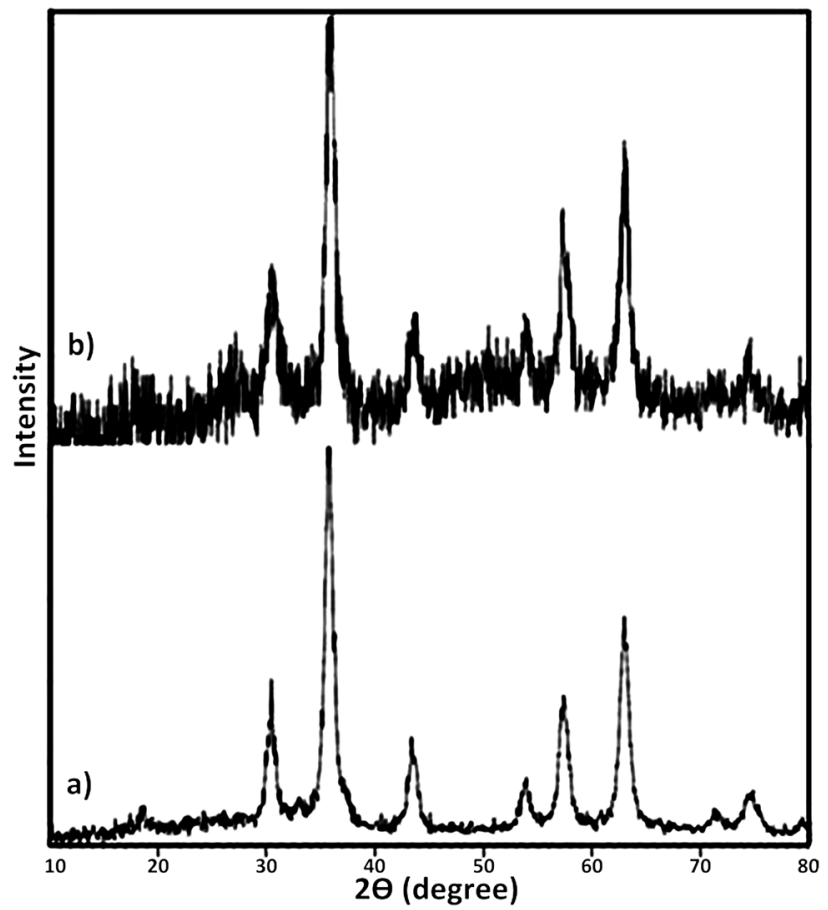

Fig. 4 XRD diffractograms of (a) $\mathrm{Fe}_{3} \mathrm{O}_{4}$ and (b) $\mathrm{Fe}_{3} \mathrm{O}_{4}\left(\mathrm{aSbF}_{x}\right.$ MNPs.

IV with H3 hysteresis loop of desorption pathway. This type of isotherm is a characteristic of mesoporous materials. Table 1 represents total pore volume $\left(V_{\text {total }}\right)$, pore diameter $\left(D_{\mathrm{BJH}}\right)$ and BET surface area $\left(S_{\mathrm{BET}}\right)$ of $\mathrm{Fe}_{3} \mathrm{O}_{4} @ \mathrm{SbF}_{x}$ MNPs. Investigation of the results shows that through modifying of the magnetite with $\mathrm{SbF}_{x}$ species, porosity of the surface was increased. Subsequently, the specific surface area was raised to $75.7 \mathrm{~m}^{2} \mathrm{~g}^{-1}$ followed by decreasing the pores diameter to $5.74 \mathrm{~nm}$.

\section{VSM analysis}

Magnetic property of $\mathrm{Fe}_{3} \mathrm{O}_{4}$ and $\mathrm{Fe}_{3} \mathrm{O}_{4} @ \mathrm{SbF}_{x}$ MNPs were also studied by vibrating sample magnetometer (VSM) analysis in the applied magnetic field up to $20 \mathrm{kOe}$ (Fig. 6). The saturation magnetization $\left(M_{\mathrm{S}}\right)$ value of $\mathrm{Fe}_{3} \mathrm{O}_{4}$ (Fig. 6a) and $\mathrm{Fe}_{3} \mathrm{O}_{4} @ \mathrm{SbF}_{x}$ (Fig. 6b) were found to be 66.976 and $23.229 \mathrm{emu} \mathrm{g}^{-1}$, respectively. The graphs are clearly showing that through the immobilization of $\mathrm{SbF}_{x}$ species on the surface of magnetite, $M_{\mathrm{s}}$ value of $\mathrm{Fe}_{3} \mathrm{O}_{4} @ \mathrm{SbF}_{x}$ was notably decreased. However, the magnetization value was still large enough for any magnetic separation.

\section{One-pot reductive-coupling of nitroarenes to azoarenes with $\mathrm{NaBH}_{4}$ catalyzed by $\mathrm{Fe}_{3} \mathrm{O}_{4} @ \mathrm{SbF}_{x}$ MNPs}

After the successful synthesis and characterization of the antimony-coated magnetite, catalytic activity of the prepared nanocatalyst was further investigated towards one-pot reductive-coupling of aromatic nitro compounds to the corresponding azoarenes.

The study was started with the preliminary aim of using antimony-coated magnetite as a catalyst towards reduction of nitroarenes to the corresponding anilines with $\mathrm{NaBH}_{4}$. Therefore, reduction of nitrobenzene with $\mathrm{NaBH}_{4}$ (as a model

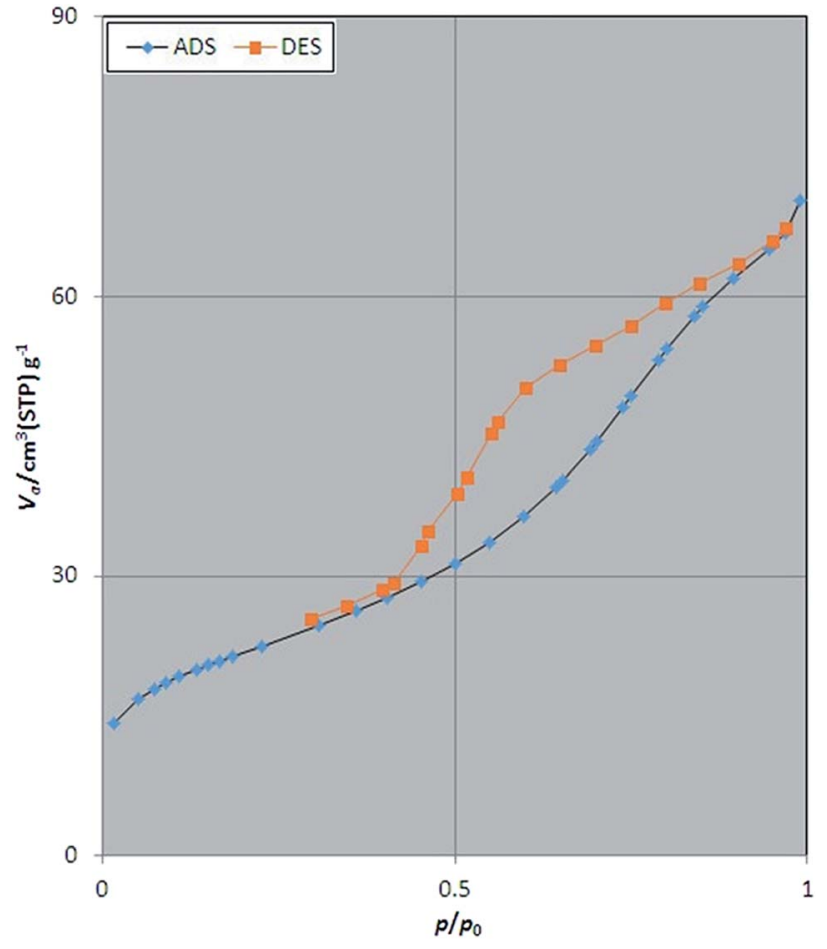

Fig. $5 \mathrm{~N}_{2}$ adsorption-desorption isotherm of $\mathrm{Fe}_{3} \mathrm{O}_{4} \mathrm{aSbF}_{x}$ MNPs.

reaction) in the presence and absence of antimony-coated magnetite was investigated with the change of reactionsolvent and amounts of nanocatalyst as well as verifying the influence of temperature (Table 2). The results of this study exhibited that progress of the reaction in the absence of Sbnanocatalyst led to unsatisfactory yield of the product. However, the influence of small amounts of nanocatalyst on the

Table 1 The surface analysis of $\mathrm{Fe}_{3} \mathrm{O}_{4} \mathrm{CSbF}_{x}$ MNPs

\begin{tabular}{llll}
\hline Sample & $S_{\text {BET }}\left(\mathrm{m}^{2} \mathrm{~g}^{-1}\right)$ & $\begin{array}{l}\text { Pore diameter } \\
(\mathrm{nm})\end{array}$ & $\begin{array}{l}\text { Total pore volume } \\
\left(\mathrm{cm}^{3} \mathrm{~g}^{-1}\right)\end{array}$ \\
\hline $\mathrm{Fe}_{3} \mathrm{O}_{4} @ \mathrm{SbF}_{x}$ MNPs & 75.739 & 5.738 & 0.1086
\end{tabular}

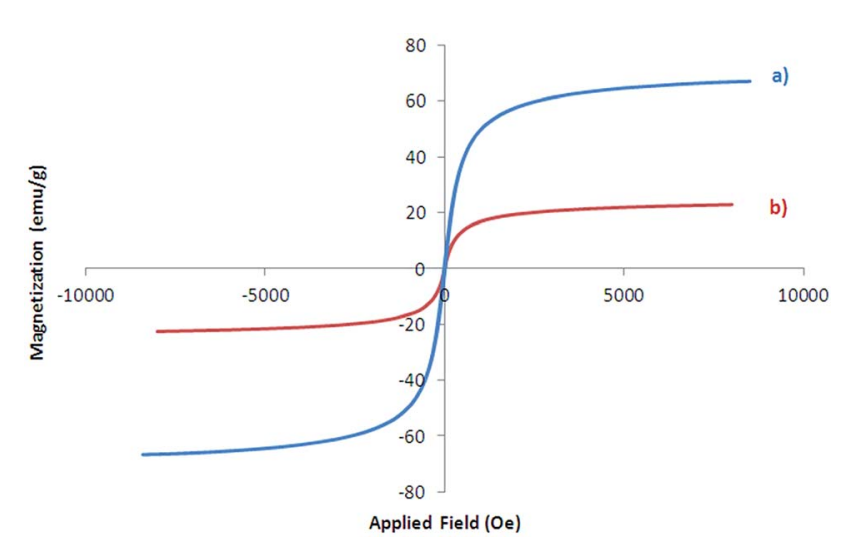

Fig. 6 Magnetization curves of (a) $\mathrm{Fe}_{3} \mathrm{O}_{4}$ and (b) $\mathrm{Fe}_{3} \mathrm{O}_{4} \mathrm{aSbF}_{x}$ MNPs. 
Table 2 Optimization experiments for reductive-coupling of nitrobenzene to azobenzene with $\mathrm{NaBH}_{4} / \mathrm{Fe}_{3} \mathrm{O}_{4} \mathrm{aSbF}_{x} \mathrm{MNPs} \mathrm{system}^{a}$

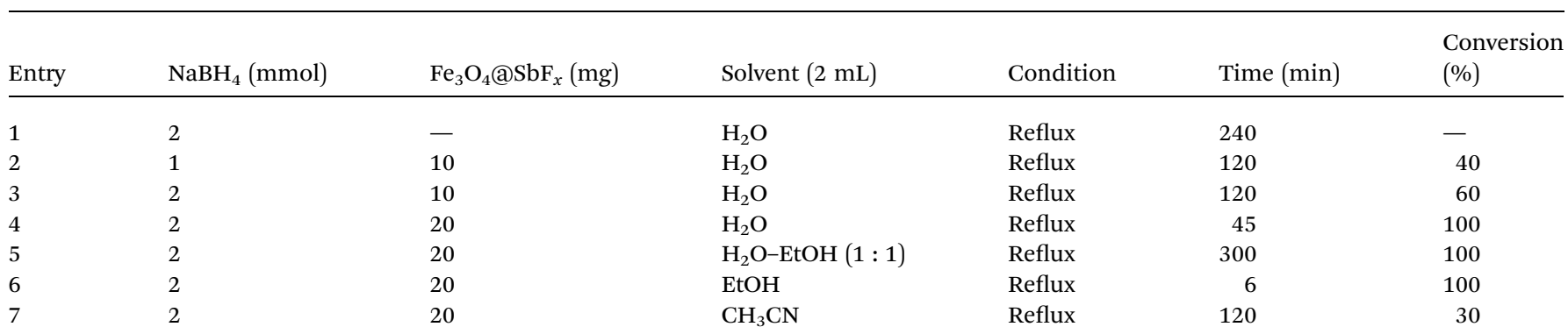

${ }^{a}$ All reactions were carried out with $1 \mathrm{mmol}$ of nitrobenzene.

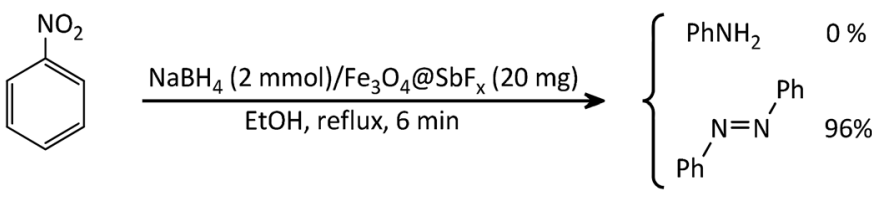

Scheme 3 Reductive-coupling of nitrobenzene to azobenzene with $\mathrm{NaBH}_{4} / \mathrm{Fe}_{3} \mathrm{O}_{4} @ \mathrm{aSbF}_{x}$ MNPs.

rate of reaction was noteworthy. In addition, it was very amazing that the product of reaction was azobenzene while it was expected to obtain aniline as a product. This transformation was clearly identifiable through the color change of the reaction to orange-red solution. As well, instrumental analysis also verified the formation of azobenzene as a sole product. The examinations represented that using $\mathrm{NaBH}_{4}(2 \mathrm{mmol})$ and $\mathrm{Fe}_{3} \mathrm{O}_{4} @ \mathrm{SbF}_{x}$ MNPs $(20 \mathrm{mg}$ ) in refluxing EtOH as a green and economic solvent was sufficient to perform one-pot reductive-coupling of nitrobenzene $(1 \mathrm{mmol})$ to azobenzene within $6 \mathrm{~min}$ and 96\% isolated yield (Scheme 3) (Table 2, entry 6).

At the next, the generality and usefulness of this synthetic protocol was further studied using structurally diverse aromatic nitro compounds at the optimized reaction conditions (Table 2, entry 6). The results of this investigation are summarized in Table 3. The table shows that all reductive-coupling of nitroarenes containing electron-withdrawing and releasing

Table 3 Reductive-coupling of nitroarenes with $\mathrm{NaBH}_{4} / \mathrm{Fe}_{3} \mathrm{O}_{4} \mathrm{QSbF}_{x}$ system ${ }^{a}$

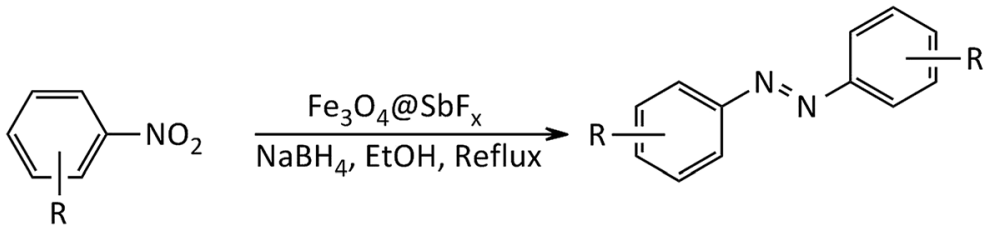

Entry Product

Time (min)

$\operatorname{Yield}^{b}(\%)$

$\mathrm{Mp}^{34}\left({ }^{\circ} \mathrm{C}\right)$

1<smiles>c1ccc(/N=N/c2ccccc2)cc1</smiles><smiles>Cc1ccccc1/N=N/c1ccccc1C</smiles><smiles>Cc1cccc(/N=N/c2cccc(C)c2)c1</smiles><smiles>Cc1ccc(/N=N/c2ccc(C)cc2)cc1</smiles> 


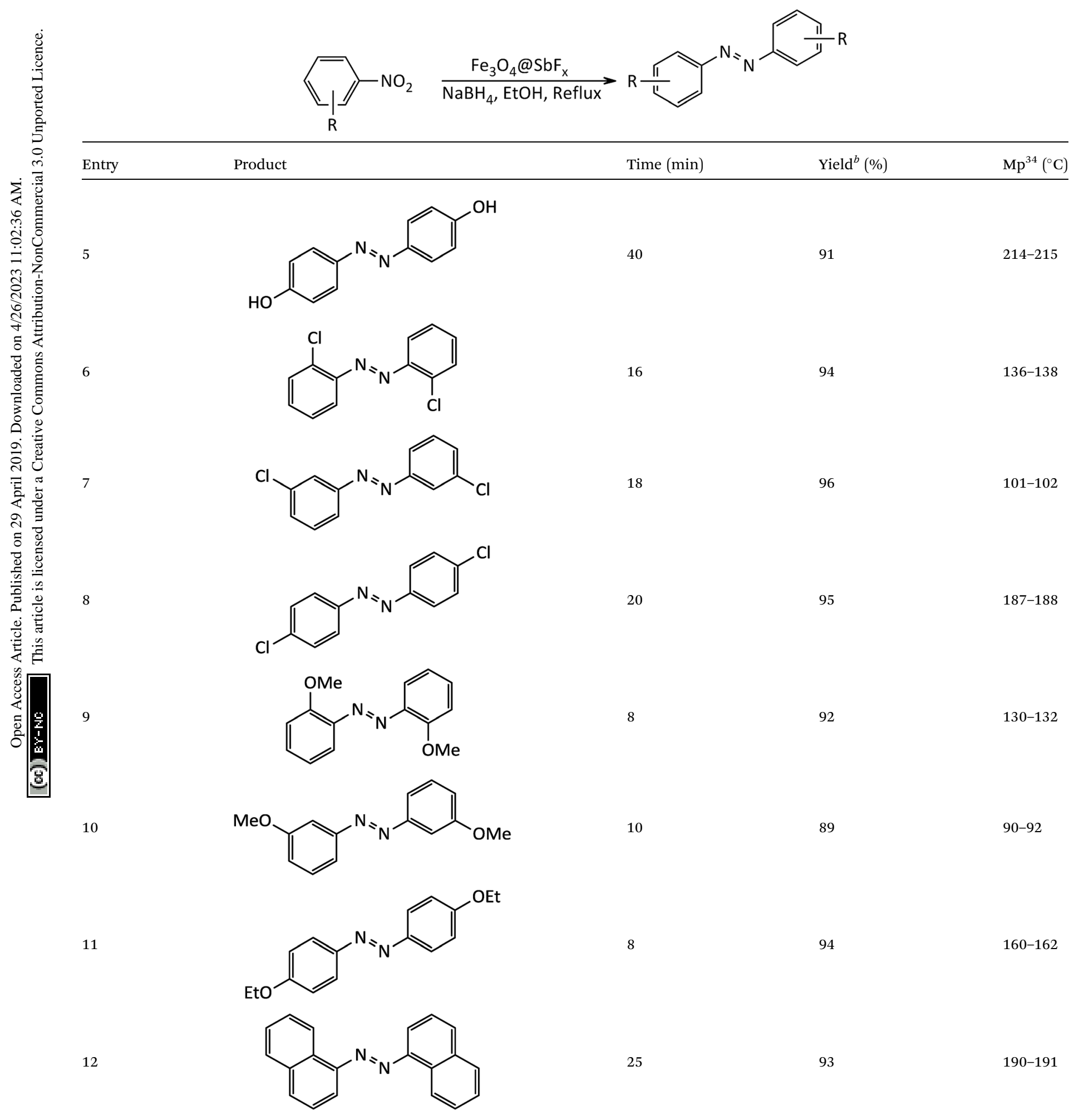




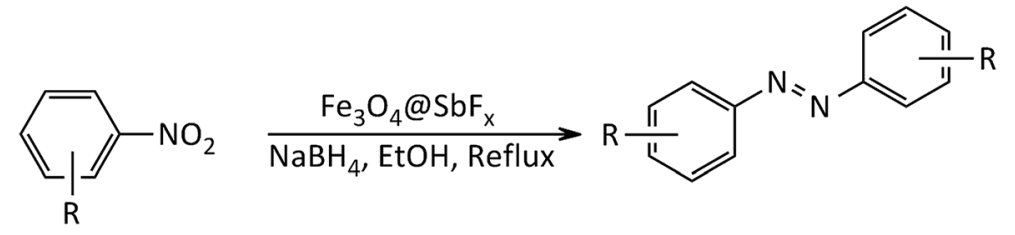

Entry Product

${ }^{a}$ All reactions were carried out with the molar ratio of subs. $/ \mathrm{NaBH}_{4}(1: 2)$ in the presence of $\mathrm{Fe}_{3} \mathrm{O}_{4} @ S b \mathrm{~F}_{x}(20 \mathrm{mg})$ in refluxing EtOH $(2 \mathrm{~mL}) .{ }^{b} \mathrm{Yields}$ refer to isolated pure products.

functionalities were carried out successfully using $\mathrm{NaBH}_{4}(2$ $\mathrm{mmol}) / \mathrm{Fe}_{3} \mathrm{O}_{4} @ \mathrm{SbF}_{x}(0.02 \mathrm{~g})$ in refluxing ethanol within 625 min giving the corresponding azoarene materials in high yields. In addition, the capability of this protocol for gram scale synthesis of azoarene materials was also investigated by one-pot reductive-coupling of nitrobenzene $(1.0 \mathrm{~g}, 8.1 \mathrm{mmol})$ with $\mathrm{NaBH}_{4}$ $(0.61 \mathrm{~g}, 16 \mathrm{mmol}) / \mathrm{Fe}_{3} \mathrm{O}_{4} @ \mathrm{SbF}_{x}(160 \mathrm{mg})$ in refluxing EtOH $(5 \mathrm{~mL})$. The obtained result exhibited that the reaction was taken place successfully within $10 \mathrm{~min}$ to afford azobenzene in $94 \%$ yield $(0.7 \mathrm{~g})$.

The exact mechanism of this synthetic protocol is not clear; however, a depicted mechanism (Scheme 4) shows a pathway for the influence of $\mathrm{NaBH}_{4} / \mathrm{Fe}_{3} \mathrm{O}_{4} @ \mathrm{SbF}_{x}$ system on one-pot reductive- coupling of nitroarenes to azoarene materials. The scheme shows that the Sb-magnetite nanocatalyst in the presence of $\mathrm{NaBH}_{4}$ was converted to the reduced-antimony species. Through the reaction of this activated nanocatalyst with nitroarene, the formation of imino-antimony intermediate was carried out. At the next, through the $[2+2]$ cycloaddition reaction of two imino-antimony species followed by skeletal rearrangement, the formation of azoarenes product was taken place.

In order to show the suitability and usefulness of $\mathrm{NaBH}_{4} / \mathrm{Fe}_{3}-$ $\mathrm{O}_{4} @ \mathrm{SbF}_{x}$ system towards one-pot synthesis of azoarene materials, the result of reductive-coupling of nitrobenzene to azobenzene was compared with the previously reported procedures (Table 4). An

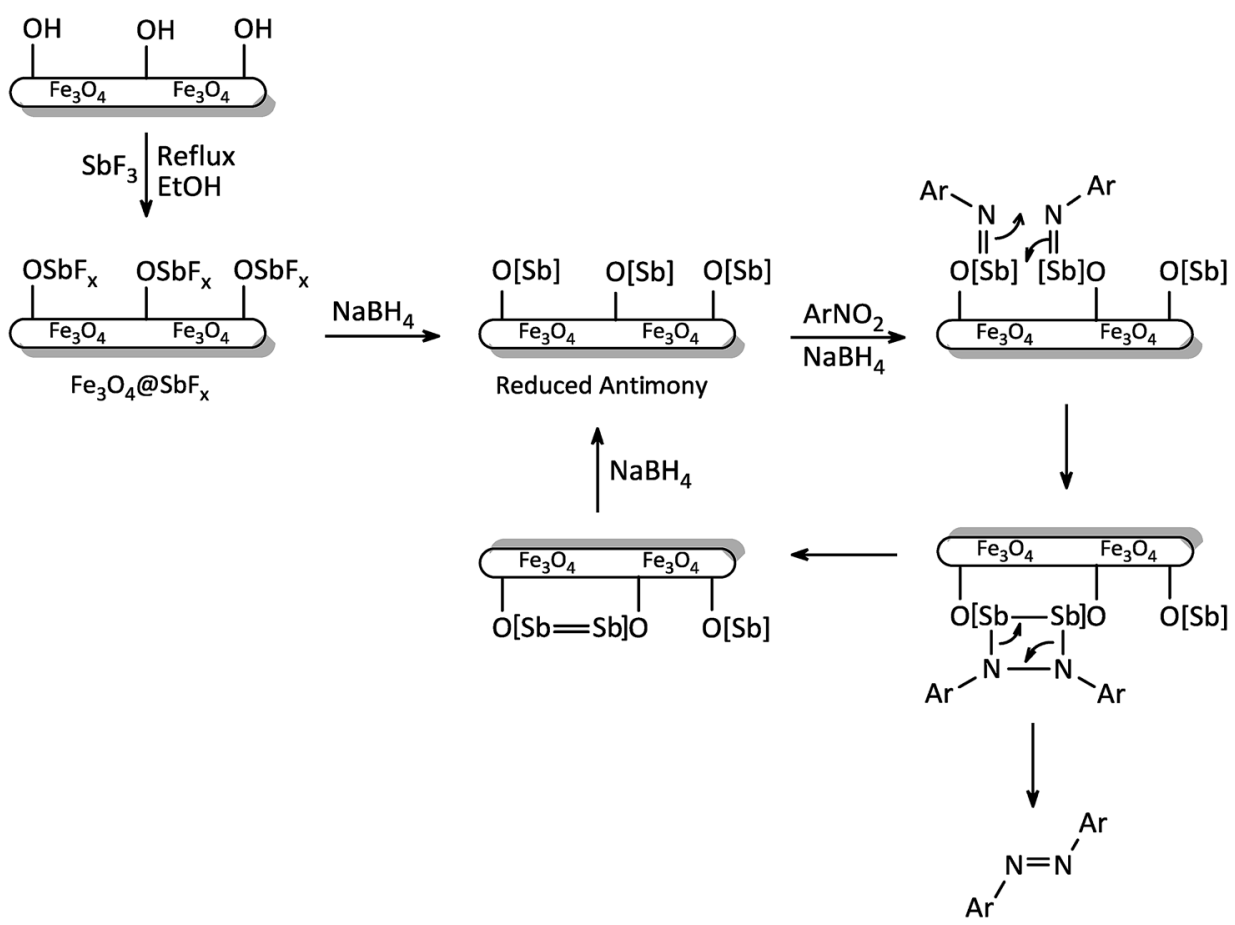

Scheme 4 The proposed mechanism for reductive-coupling of nitroarenes to azoarenes with $\mathrm{NaBH}_{4} / \mathrm{Fe}_{3} \mathrm{O}_{4} @ \mathrm{aSbF}_{x}$ system. 
Table 4 Reductive-coupling of nitrobenzene to azobenzene with $\mathrm{NaBH}_{4} / \mathrm{Fe}_{3} \mathrm{O}_{4} @ \mathrm{SbF}_{x}$ and other reported systems

2
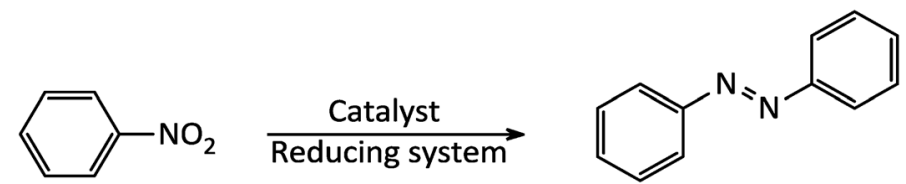

\begin{tabular}{|c|c|c|c|c|c|c|}
\hline Entry & Catalyst system & Condition & Time (min) & Yield (\%) & Reusability & Ref \\
\hline 1 & $\mathrm{NaBH}_{4} / \mathrm{Fe}_{3} \mathrm{O}_{4} @ \mathrm{SbF}_{x}$ & EtOH/reflux & 6 & 95 & 6 & $a$ \\
\hline 2 & $\mathrm{HCO}_{2} \mathrm{NH}_{4} / \mathrm{Pb}$ & $\mathrm{MeOH} /$ reflux & 60 & 92 & - & 34 \\
\hline 4 & $\mathrm{LiAlH}_{4}$ & $\mathrm{Et}_{2} \mathrm{O} /-80^{\circ} \mathrm{C}$ & - & 84 & - & 38 \\
\hline 5 & $\mathrm{NaBH}_{4}$ & $\mathrm{DMSO} / 85^{\circ} \mathrm{C}$ & 90 & 75 & - & 40 \\
\hline 6 & $\mathrm{HOCH}_{2} \mathrm{CH}_{2} \mathrm{ONa}$ & Ethylene glycol & 3 & 88 & - & 43 \\
\hline 9 & $\mathrm{Pd}(\mathrm{acac})_{2} / \mathrm{H}_{2}(1 \mathrm{~atm})$ & $\mathrm{KOH} / 70{ }^{\circ} \mathrm{C} / \mathrm{EtOH}$ & 360 & 90 & - & 49 \\
\hline 10 & $\mathrm{In}(\mathrm{OTf})_{3}-\mathrm{Et}_{3} \mathrm{SiH}$ & $\mathrm{O}_{2} / \mathrm{DMF} / 60^{\circ} \mathrm{C}$ & 720 & 84 & - & 51 \\
\hline 11 & $\mathrm{FeCl}_{2} \cdot 4 \mathrm{H}_{2} \mathrm{O} / \mathrm{Li} / \mathrm{DTBB}$ & THF/reflux & 150 & 97 & - & 52 \\
\hline 12 & 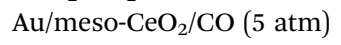 & Toluene $/ 150{ }^{\circ} \mathrm{C}$ & 300 & 99 & - & 54 \\
\hline
\end{tabular}

investigation shows that in terms of the amount of nanocatalyst, mild reaction conditions, selective formation of azobenzene, short reaction time, high yield of the product and great reusability of the Sb-nanocatalyst, the current system represents the outstanding advantages.

\section{Recyclability of $\mathrm{Fe}_{3} \mathrm{O}_{4} @ \mathrm{SbF}_{x} \mathrm{MNPs}$}

Nowadays, the recovery and reusability of the applied catalyst system has become a crucial subject in academic and industrial points of view. The green and economic aspect of this synthetic method was also studied by investigation of the reusability of $\mathrm{Fe}_{3} \mathrm{O}_{4} @ \mathrm{SbF}_{x}$ MNPs in reductive-coupling of nitrobenzene to azobenzene with $\mathrm{NaBH}_{4}$ at the optimized reaction conditions (Table 2, entry 6). After completion of the reaction, the Sbmagnetite nanocatalyst was magnetically recovered from the reaction mixture, washed with EtOAc and then dried for reusing

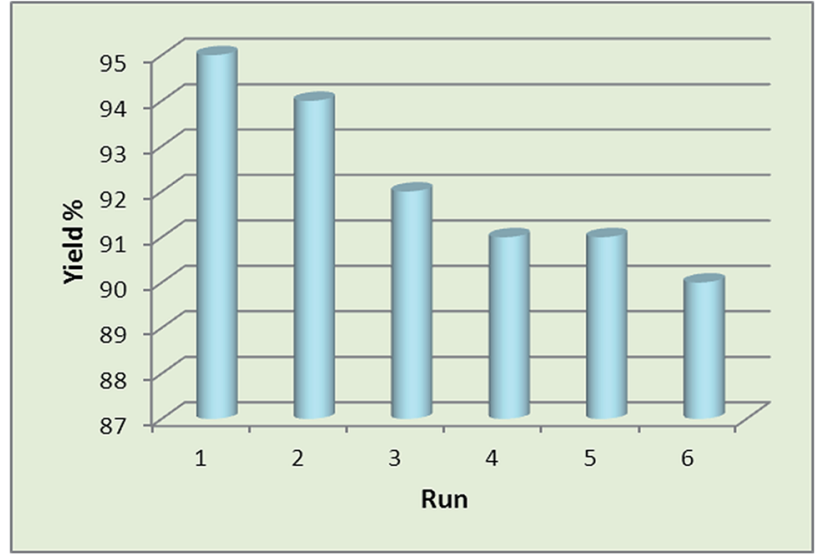

Fig. 7 Reusability of $\mathrm{Fe}_{3} \mathrm{O}_{4} \mathrm{QSbF}_{x}$ MNPs in reductive-coupling of $\mathrm{PhNO}_{2}$ with $\mathrm{NaBH}_{4}$. at the next runs. The model reaction was again charged with the fresh $\mathrm{NaBH}_{4}$, nitrobenzene, ethanol and the recovered Sbnanocatalyst. Fig. 7 shows that the nanocatalyst can be reused for six consecutive cycles without the significant loss of catalytic activity. It is also notable that due small decreasing in the activity of nanocatalyst and therefore remaining of the starting material for $1-5 \%$ over the six recycling of the nanocatalyst, isolated yield of the product was reduced for $1-5 \%$ in respect to the first run of model reaction (96\%).

\section{Conclusions}

In this study, magnetically nanoparticles of the novel antimonycoated magnetite, $\mathrm{Fe}_{3} \mathrm{O}_{4} @ \mathrm{SbF}_{x}$, were prepared. The prepared nanocomposite was then characterized using FT-IR, SEM, EDX, $\mathrm{XRD}, \mathrm{BET}$, VSM and ICP analyses. The heterogeneous Sbnanocatalyst showed an extraordinary catalytic activity toward rapid and efficient reductive-coupling of nitroarenes to azoarene materials with $\mathrm{NaBH}_{4}$ in refluxing ethanol as a green solvent. All reactions were carried out using $\mathrm{NaBH}_{4}(2 \mathrm{mmol}) /$ $\mathrm{Fe}_{3} \mathrm{O}_{4} @ \mathrm{SbF}_{x}(20 \mathrm{mg})$ within 6-25 min to give the products in high yields. This synthetic protocol offers numerous advantages in terms of the novel and easy synthesis of Sb-magnetite nanocatalyst, mild reaction conditions in comparison to the previously reported methods, using EtOH as green solvent, short reaction times, high yield of the products, simple work-up procedure and the great reusability of the nanocatalyst.

\section{Experimental}

\section{Chemicals and apparatus}

All chemicals in analytical grade were purchased from chemical companies and were used without further purification. FT-IR and ${ }^{1} \mathrm{H},{ }^{13} \mathrm{C}$ NMR spectra were recorded on Thermo Nicolet 
Nexus 670 and Bruker Avance $300 \mathrm{MHz}$ spectrometers, respectively. Melting points were measured on Electrothermal 9100 apparatus and were uncorrected. Mass spectra of the samples were obtained from Mass spectrometer (Agilent, 5975C, 20-70 $\mathrm{eV}$ ). Morphology and size distribution of nanoparticles were determined by scanning electron microscopy (SEM) using FESEM-TESCAN followed by energy-dispersive X-ray analysis (EDX). Magnetic property of materials were measured by vibrating sample magnetometer (VSM, model MDKFT) under magnetic fields up to $20 \mathrm{kOe}$. Elemental composition of the samples was determined using inductively coupled plasmaoptical emission spectrometer (ICP-OES). Specific surface area and pore size distribution of nanoparticles were determined on Belsorp-Max (Japan) instrument using $\mathrm{N}_{2}$ adsorption-desorption isotherm. X-ray diffraction (XRD) analysis was carried out by X'PertPro diffractometer. TLC was applied for monitoring of the reactions over silica gel 60 F254 aluminum sheet. All products were identified by physical and spectral data followed by comparison with authentic data.

\section{Preparation of $\mathrm{Fe}_{3} \mathrm{O}_{4} \mathrm{MNPS}$}

Magnetically nanoparticles of $\mathrm{Fe}_{3} \mathrm{O}_{4}$ were prepared via a chemical co-precipitation protocol. ${ }^{70}$ Due course, a solution of $\mathrm{FeCl}_{3} \cdot 6 \mathrm{H}_{2} \mathrm{O}$ $(0.0216 \mathrm{~mol}, 5.838 \mathrm{~g})$ and $\mathrm{FeCl}_{2} \cdot 4 \mathrm{H}_{2} \mathrm{O}(0.0108 \mathrm{~mol}, 2.147 \mathrm{~g})$ in deionized water $(100 \mathrm{~mL})$ was prepared. The solution was stirred for $10 \mathrm{~min}$ at $85{ }^{\circ} \mathrm{C}$ under $\mathrm{N}_{2}$ atmosphere. Next, aqueous ammonia $(25 \%, 10 \mathrm{~mL})$ was quickly added and the black nanoparticles of $\mathrm{Fe}_{3} \mathrm{O}_{4}$ were instantly precipitated. The resulting mixture was again stirred for $30 \mathrm{~min}$ at $85{ }^{\circ} \mathrm{C}$ under $\mathrm{N}_{2}$ atmosphere. The mixture was cooled to the room temperature and $\mathrm{Fe}_{3} \mathrm{O}_{4}$ MNPs were magnetically separated from the reaction mixture. The nanoparticles were washed with distilled water, a solution of $\mathrm{NaCl}(0.02 \mathrm{M})$ and again with distilled water. Drying under air atmosphere afforded the nanoparticles of $\mathrm{Fe}_{3} \mathrm{O}_{4}$.

\section{Synthesis of $\mathrm{Fe}_{3} \mathrm{O}_{4} @ \mathrm{SbF}_{x}$ MNPs}

To a solution of $\mathrm{SbF}_{3}(0.15 \mathrm{~g}, 0.84 \mathrm{mmol})$ in deionized water (20 $\mathrm{mL})$, magnetically nanoparticles of $\mathrm{Fe}_{3} \mathrm{O}_{4}(0.5 \mathrm{~g}, 2.15 \mathrm{mmol})$ was added. The resulting suspension was stirred for $20 \mathrm{~h}$ at $80^{\circ} \mathrm{C}$. After that, magnetically nanoparticles of $\mathrm{Fe}_{3} \mathrm{O}_{4} @ \mathrm{SbF}_{x}$ were separated by an external magnetic field, washed with deionized water and then dried at $60{ }^{\circ} \mathrm{C}$.

\section{A typical procedure for reductive-coupling of nitrobenzene to azobenzene with $\mathrm{NaBH}_{4} / \mathrm{Fe}_{3} \mathrm{O}_{4} @ \mathrm{SbF}_{x} \mathrm{MNPs}$}

A mixture of nitrobenzene $(0.123 \mathrm{~g}, 1 \mathrm{mmol})$ and $\mathrm{Fe}_{3} \mathrm{O}_{4} @ \mathrm{SbF}_{x}(0.02$ $\mathrm{g})$ in $\mathrm{EtOH}(3 \mathrm{~mL})$ was well stirred for $2 \mathrm{~min}$. $\mathrm{NaBH}_{4}(0.076 \mathrm{~g}, 2$ mmol) was then added and the resulting mixture was stirred under reflux conditions for $6 \mathrm{~min}$. During the progress of the reaction, the color of mixture was changed to orange-red showing the formation of azobenzene product. After completion of the reaction (monitored by TLC, $n$-hexane/EtOAc: $10 / 2$ ), the mixture was cooled to the room temperature. The nanocatalyst was magnetically separated from the reaction mixture followed by the addition of $\mathrm{H}_{2} \mathrm{O}(4 \mathrm{~mL})$. The mixture was stirred for additional $2 \mathrm{~min}$ and then extracted with EtOAc $(2 \times 5 \mathrm{~mL})$. The combined color extracts were dried over anhydrous $\mathrm{Na}_{2} \mathrm{SO}_{4}$. Evaporation of the solvent under reduced pressure affords the pure crystals of azobenzene in $95 \%$ yield (0.077 g, Table 3 , entry 1$)$.

\section{Conflicts of interest}

The authors declare no conflicts of interest.

\section{Acknowledgements}

We gratefully acknowledge the financial support of this work by research councils of Urmia University.

\section{References}

1 K. Hunger, Industrial Dyes: Chemistry, Properties, Applications, Wiley-VCH, Weinheim, 2003.

2 H. Zollinger, Colour Chemistry: Syntheses, Properties and Applications of Organic Dyes and Pigments, Wiley-VCH, Switzerland, 3rd edn, 2003.

3 P. F. Gordon and P. Gregory, Organic Chemistry in Colour, Springer, New York, 1983, pp. 95-162.

4 R. D. Athey Jr, Eur. Coat. J., 1998, 3, 146.

5 P. N. D. Ashutosh and J. K. Mehrotra, Colourage, 1979, 26, 25.

6 A. Jain, Y. Gupta and S. K. Jain, Crit. Rev. Ther. Drug Carrier Syst., 2006, 23, 349-400.

7 Z. F. Liu, K. Hashimoto and A. Fujishima, Nature, 1990, 347, 658-660.

8 T. Ikeda and O. Tsutsumi, Science, 1995, 268, 1873-1875.

9 H. Murakami, A. Kawabuchi, K. Kotoo, M. Kutinake and N. Nakashima, J. Am. Chem. Soc., 1997, 119, 7605-7606.

10 I. A. Banerjee, L. Yu and H. Matsui, J. Am. Chem. Soc., 2003, 125, 9542-9543.

11 F. Cisnetti, R. Ballardini, A. Credi, M. T. Gandolfi, S. Masiero, F. Negri, S. Pieraccini and G. P. Spada, Chem.-Eur. J., 2004, 10, 2011-2021.

12 J. C. Crano and R. J. Guglielmetti, Organic Photochromic and Thermochromic Compounds, Plenum Press, New York, 1999.

13 B. L. Feringa, R. A. van Delden, N. Koumura and E. M. Geertsema, Chem. Rev., 2000, 100, 1789-1816.

14 X. Liang, H. Asanuma and M. Komiyama, J. Am. Chem. Soc., 2002, 124, 1877-1883.

15 H. E. Zimmerman, R. J. Boettcher, N. E. Buehler, G. E. Keck and M. G. Steinmetz, J. Am. Chem. Soc., 1976, 98, 7680-7689.

16 B. M. Trost, R. M. Cory, P. H. Scudder and H. B. Neubold, J. Am. Chem. Soc., 1973, 95, 7813-7820.

17 K. Haghbeen and E. W. Tan, J. Org. Chem., 1998, 63, 45034505.

18 H. D. Anspon, Org. Synth. Coll., 1955, 3, 711.

19 E. Merino, Chem. Soc. Rev., 2011, 40, 3835-3853.

20 M. Rahimizadeh, H. Eshghi, A. Shiri, Z. Ghadamyari, M. M. Matin, F. Oroojalian and P. Pordeli, J. Korean Chem. Soc., 2012, 56, 716-719.

21 A. Zarei, A. R. Hajipour, L. Khazdooz, B. F. Mirjalili and A. N. Chermahini, Dyes Pigm., 2009, 81, 240-244.

22 A. Mitsutani, Catal. Today, 2002, 73, 57-63. 
23 J. Safari, S. H. Banitaba and S. D. Khalili, J. Mol. Catal. A: Chem., 2011, 335, 46-50.

24 A. Grirrane, A. Corma and H. Garcia, Science, 2008, 322, 1661-1664.

25 C. Zhang and N. Jiao, Angew. Chem., Int. Ed., 2010, 49, 61746177.

26 X. Geng and C. Wang, Org. Biomol. Chem., 2015, 13, 76197623.

27 F. Ahmed Khan and C. Sudheer, Tetrahedron Lett., 2009, 50, 3394-3396.

28 Y. Lu, J. Liu, G. Diffee, D. Liu and B. Liu, Tetrahedron Lett., 2006, 47, 4597-4599.

29 J. R. Hwu, A. R. Das, C. W. Yang, J. J. Huang and M. H. Hsu, Org. Lett., 2005, 7, 3211-3214.

30 H. J. Shine and H. E. Mallory, J. Org. Chem., 1962, 27, 23902391.

31 H. W. Galbraith, E. F. Degering and E. F. Hitch, J. Am. Chem. Soc., 1951, 73, 1323-1324.

32 P. D. Ren, S. F. Pan, T. W. Dong and S. H. Wu, Synth. Commun., 1996, 26, 3903-3908.

33 T. F. Chung, Y. M. Wu and C. H. Cheng, J. Org. Chem., 1984, 49, 1215-1217.

34 S. Gowda and D. C. Gowda, Synthesis, 2002, 460-462.

35 G. R. Srinivasa, K. Abiraj and D. C. Gowda, Synth. Commun., 2003, 33, 4221-4227.

36 G. R. Srinivasa, K. Abiraj and D. C. Gowda, Tetrahedron Lett., 2003, 44, 5835-5837.

37 G. R. Srinivasa, K. Abiraj and D. C. Gowda, Aust. J. Chem., 2004, 57, 609-610.

38 R. F. Nystrom and W. G. Brown, J. Am. Chem. Soc., 1948, 70, 3738-3740.

39 J. F. Corbett, Chem. Commun., 1968, 1257b-1258.

40 R. O. Hutchins, D. W. Lamson, L. Rua, C. Milewski and B. Maryanoff, J. Org. Chem., 1971, 36, 803-806.

41 A. C. Knipe, S. J. McGuinness and W. E. Watts, J. Organomet. Chem., 1979, 172, 463-466.

42 H. Alper and H. N. Paik, J. Organomet. Chem., 1978, 144, C18C20.

43 W. Tadros, M. S. Ishak and E. Bassili, J. Chem. Soc., 1959, 627-629.

44 A. Khan and S. Hecht, Chem.-Eur. J., 2006, 12, 4764-4774.

45 D. D. Laskar, D. Prajapati and J. S. Shandu, J. Chem. Soc., Perkin Trans. 1, 2000, 1, 67-69.

46 M. B. Sridhara, R. Suhas and D. G. C. Gowda, Eur. J. Chem., 2013, 1, 61-63.

47 J. M. Khurana and A. Ray, Bull. Chem. Soc. Jpn., 1996, 69, 407-410.

48 P. Sobota, T. Pluzinski and S. Rummel, Tetrahedron, 1981, 37, 939-942.

49 J. Wang, L. Hu, X. Cao, J. Lu, X. Li and H. Gu, RSC Adv., 2013, 3, 4899-4902.

50 N. Sakai, K. Fujii, S. Nabeshima, R. Ikeda and T. Konakahara, Chem. Commun., 2010, 46, 3173-3175.

51 N. Sakai, S. Asama, S. Anai and T. Konakahara, Tetrahedron, 2014, 70, 2027-2033.
52 Y. Moglie, C. Vitale and G. Radivoy, Tetrahedron Lett., 2008, 49, 1828-1831.

53 C. Luo, X. Ji, S. Hou, N. Eidson, X. Fan, Y. Liang, T. Deng, J. Jiang and C. Wang, Adv. Mater., 2018, 30, e1706498.

54 H. Q. Li, X. Liu, Q. Zhang, S. S. Li, Y. M. Liu, H. Y. He and Y. Cao, Chem. Commun., 2015, 51, 11217-11220.

55 V. Kalyanaraman and M. V. George, J. Org. Chem., 1973, 38, 507-514.

56 S. Wada, M. Urano and H. Suzuki, J. Org. Chem., 2002, 67, 8254-8257.

57 J. A. Gladysz, J. G. Fulcher and S. Togashi, Tetrahedron Lett., 1977, 18, 521-524.

58 M. Tamura and H. Fujihara, J. Am. Chem. Soc., 2003, 125, 15742-15743.

59 V. K. Sharma, R. A. Yngard and Y. Lin, Adv. Colloid Interface Sci., 2009, 145, 83-96.

60 M. Nasrollahzadeh, S. M. Sajadi and A. Hatamifard, J. Colloid Interface Sci., 2015, 460, 146-153.

61 A. Hatamifard, M. Nasrollahzadeh and J. Lipkowski, RSC Adv., 2015, 5, 91372-91381.

62 M. Atarod, M. Nasrollahzadeh and S. M. Sajadi, RSC Adv., 2015, 5, 91532-91543.

63 M. Atarod, M. Nasrollahzadeh and S. M. Sajadi, J. Colloid Interface Sci., 2016, 465, 249-258.

64 M. Nasrollahzadeh, M. Maham, A. Rostami-Vartooni, M. Bagherzadeh and S. M. Sajadi, RSC Adv., 2015, 5, 64769-64780.

65 M. Nasrollahzadeh, S. M. Sajadi, A. Rostami-Vartooni, M. Alizadeh and M. Bagherzadeh, J. Colloid Interface Sci., 2016, 466, 360-368.

66 M. Nasrollahzadeh, Tetrahedron Lett., 2016, 57, 337-339.

67 M. Nasrollahzadeh, New J. Chem., 2014, 38, 5544-5550.

68 C. W. Lim and I. S. Lee, Nano Today, 2010, 5, 412-434.

69 M. Nasrollahzadeh and S. M. Sajadi, J. Colloid Interface Sci., 2016, 464, 147-152.

70 Z. Shokri, B. Zeynizadeh and S. A. Hosseini, J. Colloid Interface Sci., 2017, 485, 99-105.

71 B. Zeynizadeh, I. Mohammadzadeh, Z. Shokri and S. A. Hosseini, J. Colloid Interface Sci., 2017, 500, 285-293.

72 Z. Shokri, B. Zeynizadeh, S. A. Hosseini and B. Azizi, J. Iran. Chem. Soc., 2017, 14, 101-109.

73 B. Zeynizadeh and F. Sepehraddin, J. Iran. Chem. Soc., 2017, 14, 2649-2657.

74 S. Karami, B. Zeynizadeh and Z. Shokri, Cellulose, 2018, 25, 3295-3305.

75 B. Zeynizadeh and F. Sepehraddin, J. Organomet. Chem., 2018, 856, 70-77.

76 M. Gilanizadeh and B. Zeynizadeh, New J. Chem., 2018, 42, 8553-8566.

77 G. Y. Li, Y. R. Jiang, K. L. Huang, P. Ding and L. L. Yao, Colloids Surf., A, 2008, 320, 11-18.

78 J. A. Lopez, F. Gonzalez, F. A. Bonilla, G. Zambrano and M. E. Gomez, Rev. LatinAm. Metal. Mat., 2010, 30, 60-66.

79 G. Zhang, T. Liu, T. Zhu, J. Qin, Y. Wu and C. Chen, Opt. Mater., 2008, 31, 110-113. 